Applied Radiation and Isotopes

Volume 69, Issue 11, November 2011, Pages 1596-1604

Special Issue : SAAGAS \& RCA2010

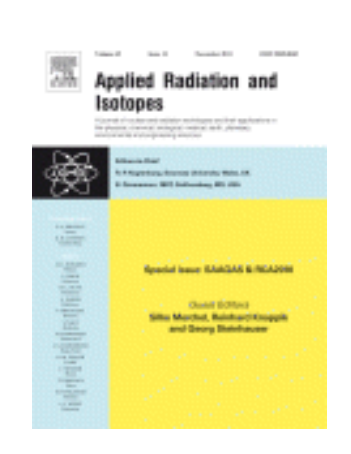

\title{
Neutron activation analysis of wheat samples
}

- C. Galinha $a^{\underline{a}, \underline{b}}$,

- H.M. Anawar

- M.C. Freitas ${ }^{\mathrm{b}}$,

- A.M.G. Pacheco

- M. Almeida-Silva ${ }^{\underline{b}}$,

- J. Coutinhoc,

- B. Maçãs $s^{c}$,

- A.S. Almeida

${ }^{a}$ CERENA-IST, Technical University of Lisbon, Av. Rovisco Pais 1, 1049-001 Lisboa, Portugal

${ }^{b}$ Instituto Tecnoclógico e Nuclear, URSN, E.N. 10, 2686-953 Sacavém, Portugal

' INRB/INIA-Elvas, National Institute of Biological Resources, Est. Gil Vaz, 7350228 Elvas, Portugal

- Available online 5 February 2011.

- $\quad$ http://dx.doi.org/10.1016/j.apradiso.2011.02.001, How to Cite or Link Using DOI 


\begin{abstract}
The deficiency of essential micronutrients and excess of toxic metals in cereals, an important food items for human nutrition, can cause public health risk. Therefore, before their consumption and adoption of soil supplementation, concentrations of essential micronutrients and metals in cereals should be monitored. This study collected soil and two varieties of wheat samples-Triticum aestivum L. (Jordão/bread wheat), and Triticum durum L. (Marialva/durum wheat) from Elvas area, Portugal and analyzed concentrations of $\mathrm{As}, \mathrm{Cr}, \mathrm{Co}, \mathrm{Fe}, \mathrm{K}, \mathrm{Na}, \mathrm{Rb}$ and Zn using Instrumental Neutron Activation Analysis (INAA) to focus on the risk of adverse public health issues. The low variability and moderate concentrations of metals in soils indicated a lower significant effect of environmental input on metal concentrations in agricultural soils. The $\mathrm{Cr}$ and $\mathrm{Fe}$ concentrations in soils that ranged from 93-117 and 26,400-31,300 mg/kg, respectively, were relatively high, but $\mathrm{Zn}$ concentration was very low (below detection limit $<22 \mathrm{mg} / \mathrm{kg}$ ) indicating that soils should be supplemented with $\mathrm{Zn}$ during cultivation. The concentrations of metals in roots and straw of both varieties of wheat decreased in the order of $\mathrm{K}>\mathrm{Fe}>\mathrm{Na}>\mathrm{Zn}>\mathrm{Cr}>\mathrm{Rb}>\mathrm{As}>\mathrm{Co}$. Concentrations of $\mathrm{As}, \mathrm{Co}$ and $\mathrm{Cr}$ in root, straw and spike of both varieties were higher than the permissible limits with exception of a few samples. The concentrations of $\mathrm{Zn}$ in root, straw and spike were relatively low $(4-30 \mathrm{mg} / \mathrm{kg})$ indicating the deficiency of an essential micronutrient $\mathrm{Zn}$ in wheat cultivated in Portugal. The elemental transfer from soil to plant decreases with increasing growth of the plant. The concentrations of various metals in different parts of wheat followed the order: Root $>$ Straw $>$ Spike. A few root, straw and spike samples showed enrichment of metals, but the majority of the samples showed no enrichment. Potassium is enriched in all samples of root, straw and spike for both varieties of wheat. Relatively to the seed used for cultivation, Jordão presented higher transfer coefficients than Marialva, in particular for $\mathrm{Co}, \mathrm{Fe}$, and $\mathrm{Na}$. The Jordão and Marialva cultivars accumulated not statistically significant different concentrations of different metals. The advantages of using INAA are the multielementality, low detection limits and use of solid samples (no need of digestion).
\end{abstract}

\title{
Keywords
}

- INAA;

- Micronutrient;

- Metals;

- Nutrition;

- Transfer coefficient;

- Wheat varieties

http://www.sciencedirect.com/science/article/pii/S0969804311000765 